\author{
Stanislava Rangelova* \\ University of Augsburg \\ Augsburg, Germany \\ and \\ BMW Group \\ Munich, Germany
}

\section{Elisabeth Andre}

University of Augsburg

Augsburg, Germany

Presence, Vol. 27, No. I, Winter 2018, 15-31 doi: 10.1 | 62/PRES_a_00318

(c) 2019 by the Massachusetts Institute of Technology

\section{A Survey on Simulation Sickness in Driving Applications with Virtual Reality Head-Mounted Displays}

\begin{abstract}
This article discusses factors related to simulation sickness in virtual reality driving simulations with head-mounted displays. Simulation sickness is a well-known phenomenon that has physiological effects on users, such as disorientation, headache, and nausea. There are three major theories why simulation sickness arises. Previous research on this phenomenon has mostly concentrated on driving or flying simulators with standard computer displays. It is, therefore, possible to conclude that any simulated environment could have such an effect, and virtual reality should not be considered an exception to such problems. While virtual reality has had and will continue to have a positive impact on the development and testing of new automotive interior concepts, simulation sickness is a significant drawback. Despite the advances in technology, discomfort from using head-mounted displays has yet to be resolved. A review of these displays in the context of virtual reality driving applications over the recent years will be presented. Moreover, characterization and comparison of approaches to mitigate simulation sickness will be given in the text. Concluding suggestions for future work on the correlation between simulation sickness and a virtual driving environment will be provided.
\end{abstract}

\section{Introduction}

Virtual reality (VR) is a computer-simulated environment where one interacts within the environment similarly as he or she would in the "real world." The term "VR" was first used in 1987 by Jaron Lanier, a computer scientist who is considered a founding father of the field of VR, as a term for an environment simulated through computer graphics. Presently, VR has developed to the point where the user can be disconnected from the real world. This type of simulated environment has the potential to be applied in many diverse industries (e.g., architecture, healthcare, automotive, military, and entertainment) for research, evaluation, and visualization. The trend for head-mounted displays (HMD) began in the last few years and virtual reality has since then continually increased in popularity. HMDs offer a stereoscopic 3-dimensional (3D) environment with a wide field of view (FOV) and low-latency fast-tracking system for better interaction with the virtual environment (Davis, Nesbitt, \& Nalivaiko, 2015).

One of the application areas that benefits significantly from the VR technology is driving simulation. This type of simulation with an integrated HMD is

\footnotetext{
${ }^{*}$ Correspondence to stanislava.rangelova@bmw.de.
} 
meant to create an interactive driving environment in the form of a virtual prototype where the driver is fully immersed in the driving scenario and can thus interact naturally with the setting above. Driving simulators enable the testing of new automotive interfaces in a variety of fully simulated driving scenarios, which include benefits such as the ability to repeatedly conduct tests as often as necessary and the possibility to collect and record the individual driving sessions' data with the purpose of evaluation. Furthermore, the driving sessions run under an entirely controlled environment where the simulation can be paused, stopped, or repeated as many times as necessary. In the virtual environment changes in the objects can be easily made within a short time, as well as changes in the environment itself. Therefore, such an environment guarantees higher flexibility in the testing process of new interface concepts.

Additionally, development costs can be reduced because most errors can be discovered at an early stage of development (De Winter, Van Leeuwen, \& Happee, 2012). Despite all advantages of VR driving simulators, one important side effect of VR must be considered: simulation sickness. This seemingly trivial side effect plays a vital role in the usability of VR driving systems. Simulation sickness is a particular discomfort (e.g., headache, nausea, and eye strain) that can be experienced during or after VR sessions. The addition of VR to the driving simulators decisively raises the probability of simulation sickness. Due to the considerable influence of these symptoms to a person's mental and physical state during driving sessions, it is pertinent to find a solution to these symptoms, whether by elimination or reduction to a minimum.

A short overview of simulation sickness will be given followed by a literature review of driving simulations with HMDs from the past five years. The review is organized into the following categories: objective, author and year of publication, HMD type, age and a total number of participants, measurement tool, and findings. A table of mitigation techniques will be presented, followed by a discussion of the listed techniques regarding HMD driving applications. In the end, a brief examination of possible directions for future research will be given.

\section{Simulation Sickness}

Simulation sickness or visually induced motion sickness (VIMS) is a type of motion sickness that does not require a true motion but requires a wide FOV to develop (Biocca, 1992). It is considered to be polysymptomatic (i.e., causing many symptoms) which commonly includes nausea, disorientation, headache, and general discomfort (Kennedy and Fowlkes, 1992). Throughout the article, we use the term "simulation sickness" to refer to VIMS and simulation sickness.

Simulation sickness symptoms are similar to those of motion sickness, but there are also a few critical points at which to differentiate the two. Motion sickness symptoms are mostly gastrointestinal (e.g., stomach awareness, nausea, and eructation) while simulation sickness symptoms include motion sickness symptoms and others, such as headache, eye strain, and blurred vision, which are visually induced (Cobb, Nichols, Ramsey, \& Wilson, 1999; Kennedy, Berbaum, Lilienthal, Dunlap, \& Mulligan, 1987; Uliano, Lambert, Kennedy, \& Sheppard, 1986). Symptoms, such as general discomfort, eye strain, and difficulty in concentrating, are more likely to be experienced by a person who is fully immersed in a virtual environment (Jinjakam \& Hamamoto, 2012). The problem of simulation sickness has not been solved entirely and there is no solution that prevents every user from experiencing discomfort. Simulation sickness in a virtual environment should not be underestimated due to unexplained symptoms' duration, but should be considered as serious as any other medical issue.

\section{I Theories}

Cue conflict theory (also referred to as sensory conflict, neural mismatch, and sensory rearrangement theory) is the most well-known theory regarding simulation sickness. Originally developed to explain motion sickness (Reason \& Brand, 1975), it was later discovered to also apply to simulation sickness. A so-called "mismatch" could arise between visual, vestibular, and muscular proprioceptive systems, all of which can incite a perceived increase of discomfort as a response from the body (Crampton, 1990). 
Another theory, which was adopted from motion sickness origin theories, is the poison theory. Poison theory, also called evolutionary theory, suggests that unnatural movement could cause an emesis response. According to this theory, the human body has not had enough time to accommodate itself to everyday modern transportation (e.g., car, bus, and airplane) which are being used nowadays. Therefore, the body misreads the sensory input information as if it were being poisoned. The biological impulse is to empty the stomach content to eliminate the intoxicants (Treisman, 1977).

Decades later, Riccio and Stoffregen (1991) disagreed with the cue conflict theory and suggested another theory, known as the postural instability theory. The theory states that the primary purpose of the human body is to maintain its postural stability. When this balance is disturbed, the person feels discomfort (e.g., disorientation, nausea, and dizziness). Every novel environment, such as a virtual environment, presents the human with the challenge of maintaining balance within it (Brooks et al., 2010).

\subsection{Factors Related to Simulation Sickness}

Factors that could induce simulation sickness are grouped into three categories: personal traits, systematic features unique to the simulation, and task objectives (Kolasinski, 1995). The first category involves individual factors which comprise gender, age, illness, concentration level, ethnicity, experience with real-world tasks, adaptation, mental rotation ability, perceptual style, as well as postural stability. The second category contains system-related factors which include lag, flicker, calibration, ergonomics, binocular viewing, color, interocular distance, contrast, FOV, motion platform, positiontracking error, refresh rate, scene content, frame rate, and viewing region. The final category is named taskrelated factors which include degree of control, duration, global visual flow, head movement, luminance level, unusual maneuvers, rate of linear or rotational acceleration, method of movement, self-movement speed, sitting vs. standing position, vection, and type of application (Costello, 1997; Johnson, 2005). For the complete list consisting of 40 factors related to simulation sickness in virtual environments, we refer to Kolasinski (1995).

A detailed investigation of each factor is however out of the scope of this article.

\section{Simulation Sickness Associated with Driving Simulation using HMDs}

Research in VR driving simulation and more specifically, driving simulation with HMDs, has experienced growth in recent years. A few studies are focusing on VR driving simulator evaluation with HMD. Simulation sickness in VR driving applications should be considered more complex than other comparable sicknesses in other VR applications, namely because of visual and physical motion cues which add a possibility of motion sickness outbreak. Therefore, the discomfort can be induced from a multitude of sources, such as visual-vestibular mismatch or visualproprioceptive mismatch (Keshavarz, Hecht, \& Lawson, 2014).

Table 1 summarizes a review of simulation sickness associated with VR HMD driving applications during the period from 2012 to 2017 . This period has been chosen due to lower hardware parameters of HMDs preceding 2012, such as FOV, refresh rate, and visual graphics quality. For comparison, Oculus Rift Development Kit 1 $(\mathrm{DKl})$, released in 2013 , has a resolution of $640 \times 800$ per eye, a refresh rate of $60 \mathrm{~Hz}$, a latency (end-to-end) of 50-60 ms, a FOV of $110^{\circ}$, and weighs $380 \mathrm{~g}$ (Popa, 2014). The consumer version of Oculus Rift (CVI), released in 2016, has a resolution of $1080 \times 1200$ pixels per eye, a refresh rate of $90 \mathrm{~Hz}$, a latency (end-to-end) of around $25 \mathrm{~ms}$, a FOV of $110^{\circ}$, and weighs $360 \mathrm{~g}$. Parameters related to simulation sickness outbreak, such as latency, are reduced by almost $50 \%$ with the newer HMD model (Oculus, 2018).

In the literature, immersion often refers to a physiological state characterized by perceiving oneself to be enveloped by, included in, and interacting with a stimulating environment (Witmer \& Singer, 1998). A sense of presence refers to experiencing the simulated environment rather than the actual (real-world) environment. 
Table I. Overview of Simulation Sickness Evaluation in VR HMD Driving Applications

\begin{tabular}{|c|c|c|c|c|c|}
\hline Objective & HMD & $N(\mathrm{f} / \mathrm{m})$ & Measurement & Findings & Reference \\
\hline $\begin{array}{l}\text { Investigation of the } \\
\text { sense of presence and } \\
\text { physiological } \\
\text { response induced by } \\
\text { an immersive virtual } \\
\text { environment. }\end{array}$ & $\begin{array}{l}\text { Oculus Rift } \\
\text { CVl }\end{array}$ & $\begin{array}{l}5 \text { (all male) } \\
M=31.2 \\
S D=4.6\end{array}$ & $\begin{array}{l}\text { - Heart rate } \\
\text { - EDA } \\
\text { - A customized } \\
\text { presence and } \\
\text { cybersickness } \\
\text { questionnaire }\end{array}$ & $\begin{array}{l}\text { HMD increased the sense of } \\
\text { presence. None of the } \\
\text { participants reported } \\
\text { cybersickness symptoms. } \\
\text { The emergency } \\
\text { maneuvering increased the } \\
\text { response of heart rate and } \\
\text { electrodermal activity. }\end{array}$ & $\begin{array}{c}\text { Eudave \& } \\
\text { Valencia } \\
(2017)\end{array}$ \\
\hline $\begin{array}{l}\text { Comparison of VR and } \\
\text { non-VR driving } \\
\text { simulations influence } \\
\text { physiological } \\
\text { responses, simulation } \\
\text { sickness, and driving } \\
\text { performance. }\end{array}$ & $\begin{array}{l}\text { Oculus Rift } \\
\text { Development } \\
\text { Kit } 2 \text { (DK2) }\end{array}$ & $\begin{array}{l}94(24 / 70) \\
M=24.8 \\
S D=4.7\end{array}$ & - SSQ & $\begin{array}{l}\text { HMD induced significantly } \\
\text { more discomfort than the } \\
\text { stereoscopic 3D } \\
\text { simulation. }\end{array}$ & $\begin{array}{l}\text { Weidner } \\
\text { et al. } \\
(2017)\end{array}$ \\
\hline $\begin{array}{l}\text { Evaluation of VR } \\
\text { driving simulation in } \\
\text { relation to user's } \\
\text { immersion in } \\
\text { low-cost setup. }\end{array}$ & HTC Vive & $\begin{array}{l}20(5 / 14 ; \\
\text { one-not } \\
\text { reported }) \\
M=25.1 \\
S D=3.2\end{array}$ & - SSQ & $\begin{array}{l}\text { No significant difference } \\
\text { between HMD and flat } \\
\text { screen conditions } \\
\text { regarding simulation } \\
\text { sickness was reported. }\end{array}$ & $\begin{array}{c}\text { Walch et al. } \\
(2017)\end{array}$ \\
\hline $\begin{array}{l}\text { Evaluation of } \\
\text { additional visual } \\
\text { assets on simulation } \\
\text { sickness outbreak in } \\
\text { HMD driving } \\
\text { simulation. }\end{array}$ & $\begin{array}{l}\text { Oculus Rift } \\
\text { DK2 }\end{array}$ & $\begin{array}{l}72(18 / 54) \\
M=25.3 \\
S D=5.2\end{array}$ & $\begin{array}{l}\text { - SSQ } \\
\text { - A customized } \\
\text { questionnaire }\end{array}$ & $\begin{array}{l}\text { Significantly reduced } \\
\text { simulation sickness onset } \\
\text { in a city VR environment } \\
\text { with additional assets (e.g., } \\
\text { pedestrians and other } \\
\text { cars). No relation found } \\
\text { between motion sickness } \\
\text { history and simulation } \\
\text { sickness. }\end{array}$ & $\begin{array}{l}\text { Ihemedu- } \\
\text { Steinke } \\
\text { et al. } \\
(2017)\end{array}$ \\
\hline $\begin{array}{l}\text { HMDs for } \\
\text { human-cockpit } \\
\text { interactions } \\
\text { validation while } \\
\text { driving in an } \\
\text { immersive } \\
\text { environment. }\end{array}$ & $\begin{array}{l}\text { Oculus Rift } \\
\text { DK l }\end{array}$ & $\begin{array}{l}20(3 / 17) \\
M=28.3 \\
S D=3.6\end{array}$ & - SSQ & $\begin{array}{l}\text { Simulation sickness was } \\
\text { significantly lower with PC } \\
\text { setup than with HMD. } \\
\text { Reported awkwardness } \\
\text { when the users did not see } \\
\text { their own hands. }\end{array}$ & $\begin{array}{l}\text { Reich, } \\
\text { Buchholz, } \\
\text { \& Stark } \\
\text { (2017) }\end{array}$ \\
\hline $\begin{array}{l}\text { Motion sickness } \\
\text { comparison between } \\
\text { a CAVE environment } \\
\text { and an HMD. }\end{array}$ & $\begin{array}{l}\text { Oculus Rift } \\
\text { DK } 2\end{array}$ & $\begin{array}{l}24(6 / 18) \\
M=36 \\
S D=9\end{array}$ & - SSQ & $\begin{array}{l}\text { Simulation sickness might } \\
\text { be increased with yaw } \\
\text { acceleration increasing. }\end{array}$ & $\begin{array}{l}\text { Colombet, } \\
\text { Kemeny, } \\
\text { \& George } \\
(2016)\end{array}$ \\
\hline
\end{tabular}


Table I. Continued.

\begin{tabular}{|c|c|c|c|c|c|}
\hline Objective & HMD & $N(\mathrm{f} / \mathrm{m})$ & Measurement & Findings & Reference \\
\hline $\begin{array}{l}\text { An investigation of } \\
\text { galvanic cutaneous } \\
\text { stimulation and } \\
\text { auditory stimulation } \\
\text { in mitigation } \\
\text { simulation sickness. }\end{array}$ & $\begin{array}{l}\text { VR-based } \\
\text { visual system }\end{array}$ & $\begin{array}{l}15(6 / 9) \\
M=23.2\end{array}$ & $\begin{array}{l}\text { - SSQ } \\
\text { - Head sway }\end{array}$ & $\begin{array}{l}\text { Simulation sickness is } 47 \% \\
\text { less with galvanic } \\
\text { cutaneous stimulation and } \\
\text { audio stimulation in a } \\
\text { static driver simulator. }\end{array}$ & $\begin{array}{l}\text { Galvez- } \\
\text { Garcia } \\
(2015)\end{array}$ \\
\hline $\begin{array}{l}\text { Development and } \\
\text { evaluation of a VR } \\
\text { driving simulator } \\
\text { with HMD. }\end{array}$ & $\begin{array}{l}\text { Oculus Rift } \\
\text { DK } 2\end{array}$ & $\begin{array}{l}25(5 / 20) \\
M=37.6\end{array}$ & - PQ & $\begin{array}{l}\text { Four out of five females felt } \\
\text { sick in the first five } \\
\text { minutes of the test. Almost } \\
\text { all participants with no } \\
\text { prior experience with } \\
\text { HMD got simulation sick. }\end{array}$ & $\begin{array}{l}\text { Ihemedu- } \\
\text { Steinke } \\
\text { et al. } \\
(2015)\end{array}$ \\
\hline $\begin{array}{l}\text { Comparison between a } \\
\text { static HMD and a } \\
\text { medium range FOV } \\
\text { driving simulator } \\
\text { regarding simulation } \\
\text { sickness. }\end{array}$ & $\begin{array}{l}\text { Oculus Rift } \\
\text { DK I }\end{array}$ & $\begin{array}{l}14(2 / 12) \\
M=24.4 \\
S D=2.3\end{array}$ & $\begin{array}{l}\text { - Customized } \\
\text { questionnaire } \\
\text { - Vehicle } \\
\text { acceleration } \\
\text { - Head } \\
\text { (vestibular) } \\
\text { acceleration }\end{array}$ & $\begin{array}{l}\text { Simulation sickness (SS) } \\
\text { increased with the VR } \\
\text { driving simulator. Users of } \\
\text { the VR driving simulator } \\
\text { felt more discomfort such } \\
\text { as nausea, dizziness and } \\
\text { eye strain. The level of } \\
\text { immersion was higher with } \\
\text { the VR driving simulator } \\
\text { and it could deliver a } \\
\text { better experience despite } \\
\text { SS occurrence. }\end{array}$ & $\begin{array}{l}\text { Aykent } \\
\text { et al. } \\
(2014)\end{array}$ \\
\hline $\begin{array}{l}\text { Assess the extent to } \\
\text { which level the } \\
\text { vehicle in a loop } \\
\text { elicits realistic driving } \\
\text { responses. }\end{array}$ & NVIS SX111 & $\begin{array}{l}44(15 / 29) \\
M=29 \\
S D=10\end{array}$ & - SSQ & $\begin{array}{l}\text { Disorientation cluster } \\
\text { symptoms were more } \\
\text { severe than Nausea or } \\
\text { Oculomotor ones. } 4 \% \\
\text { stopped the experiment } \\
\text { due to severe symptoms, } \\
94 \% \text { had minor symptoms. } \\
\text { No significant difference } \\
\text { between driving in a } \\
\text { simple and a complex } \\
\text { virtual world. }\end{array}$ & $\begin{array}{c}\text { Sieber et al. } \\
(2013)\end{array}$ \\
\hline
\end{tabular}

The HMD model, the number $(N)$, the gender $(\mathrm{f}=$ female and $\mathrm{m}=$ male $)$, and the age $(M=$ mean age and $S D=$ standard deviation) of the subjects and the measurements are mentioned. EDA = electrodermal activity.

A virtual environment that creates a higher level of immersion will create a greater sense of presence. The sense of presence can be measured by the subjec- tive seven-point scale questionnaire called Presence Questionnaire (PQ). The original version of the PQ includes 32 items divided into four major factor 
categories: control, sensory, distraction, and realism factors (Witmer \& Singer, 1998). Some of the items appear in two or three categories of factors. For example, the item "How completely were you able to actively survey or search the environment using vision?" appears in control, sensory, and realism factor categories.

The correlation between simulation sickness in VR and the sense of presence appears to be complicated and indirect. A lower sense of presence may induce disorientation, which may increase the sickness onset (Nichols, Haldane, \& Wilson, 2000). A survey such as that conducted by Schuemie, Van der Straaten, Krijn, and Van der Mast (2001) has shown that the correlation between simulation sickness and presence is controversial. However, another study found a positive correlation ( Lin, Duh, Parker, Abi-Rached, \& Furness, 2002). They conclude that the relationship between simulation sickness and presence may significantly change with different levels of interactivity in the virtual environment.

A well-known scale for measuring simulation sickness severity is the Simulator Sickness Questionnaire (SSQ). The questionnaire contains 16 items divided into three categories: Disorientation, Oculomotor, and Nausea. Each item represents a symptom and it is graded on a 4-point Likert scale (none, slight, moderate, and severe) (Kennedy, Lane, Berbaum, \& Lilienthal, 1993).

An essential criterion for including a study in our review was not only the year of publication, but also the occurrence of simulation sickness. It can be noted that most of the studies have a small sample size, and therefore, they are not statistically significant to provide a general conclusion. Nevertheless, these studies provide valuable insights into the influence of VR driving applications on simulation sickness and how it is measured.

In Table 1, Aykent et al. (2014) used a questionnaire which has been built and modified from the following articles: Kennedy et al. (1993); Kim, Moon, Kim, and Lee (2010); and XSens (2010). The questionnaire used in the study included two questions about the visual and immersive qualities of the scene. Additionally, it contained nine questions with the response range from 1 (too little/very bad) to 10 (too strong/very good).

\section{Mitigation Techniques against Simulation Sickness}

Despite technological advances, simulation sickness has still not been completely eradicated. At first glance, the specific symptoms related to this sickness do not seem inherently dangerous for the VR users during the immersion. However, upon further examination, simulation sickness is not only an extensive unpleasant experience among users, but can also have a longlasting, and potentially dangerous effect well after the end of the simulation (McCauley, 1984; Crowley, 1987; Kennedy \& Lilienthal, 1995). Some sources warn about specific dangers for users who drive after extended exposure to a virtual environment. At least until 2005, there were no reported car accidents due to simulation sickness within twelve hours after the simulation's conclusion (Johnson, 2005).

For reducing simulation sickness onset in virtual environments, some mitigation techniques can be applied. Not every technique is suitable or has been tested with VR driving applications. Table 2 is adapted from a review study on behavioral techniques by Keshavarz (2016), where feasible solutions of reducing simulation sickness have been discussed. Additional techniques are included for which a positive contribution to the minimization of simulation sickness has been reported. The table excludes the technique of galvanic cutaneous stimulation due to an unpleasant feeling that can occur. This technique stimulates a large diameter of the skin surface, which affects the skin's nerve fibers, with electric current with values below the motor threshold (Gálvez-García, 2015 ).

Regan (1995) found that hyoscine had alleviated not only nausea, but also sickness symptoms, such as eye strain, stomach awareness, disorientation, and headaches induced by the HMD. For this evaluation, a malaise scale and the SSQ were used to measure the discomfort outbreak. The malaise scale measures the level of malaise on a scale from 1 (no symptoms) to 6 (being sick). None of the participants had been previously exposed to VR. The hyoscine has a quicker mitigation effect than adaptation (Regan, 1995). Besides the relieving effect, other side effects such as drowsiness, dizziness, blurred vision, 


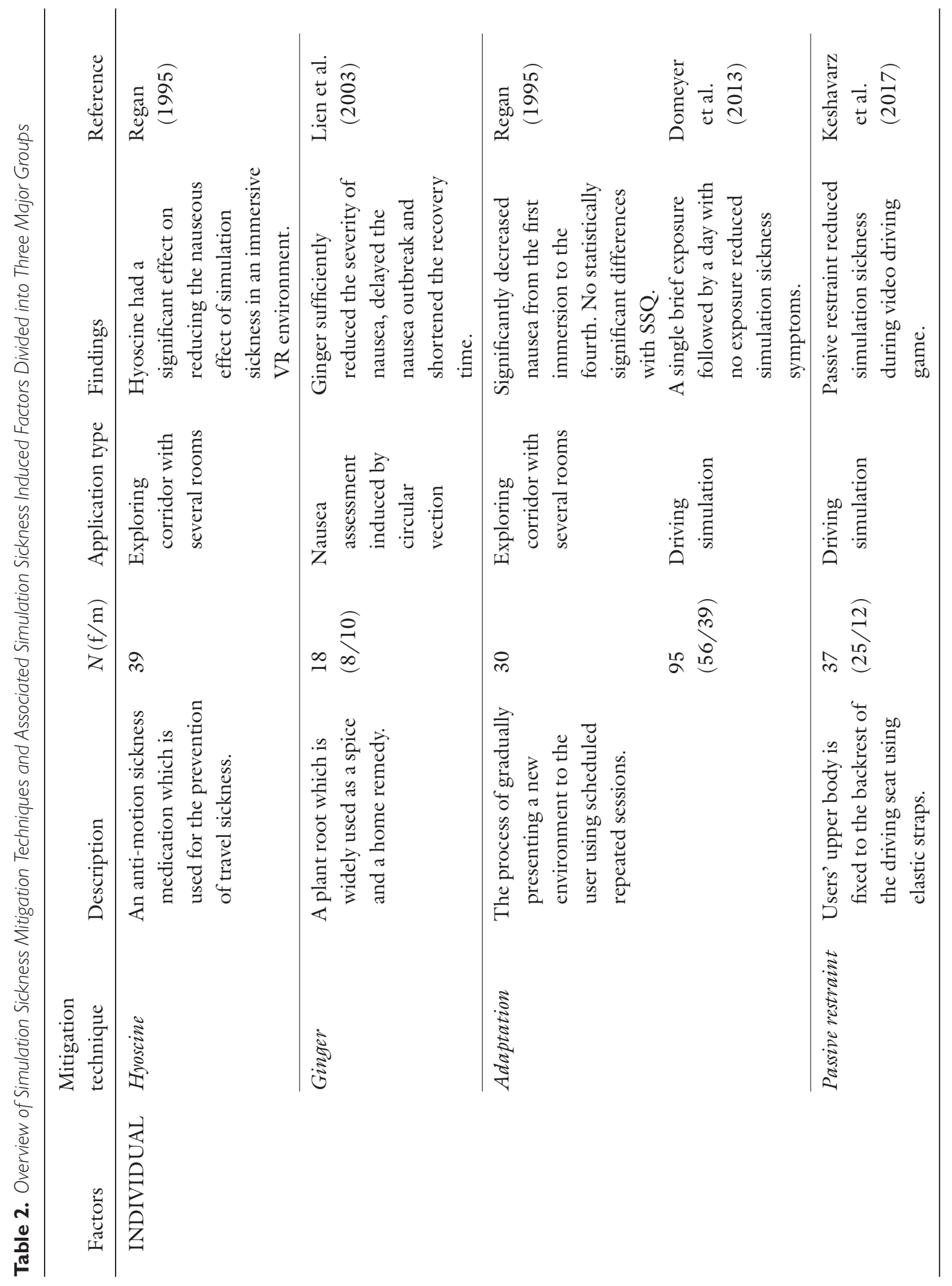




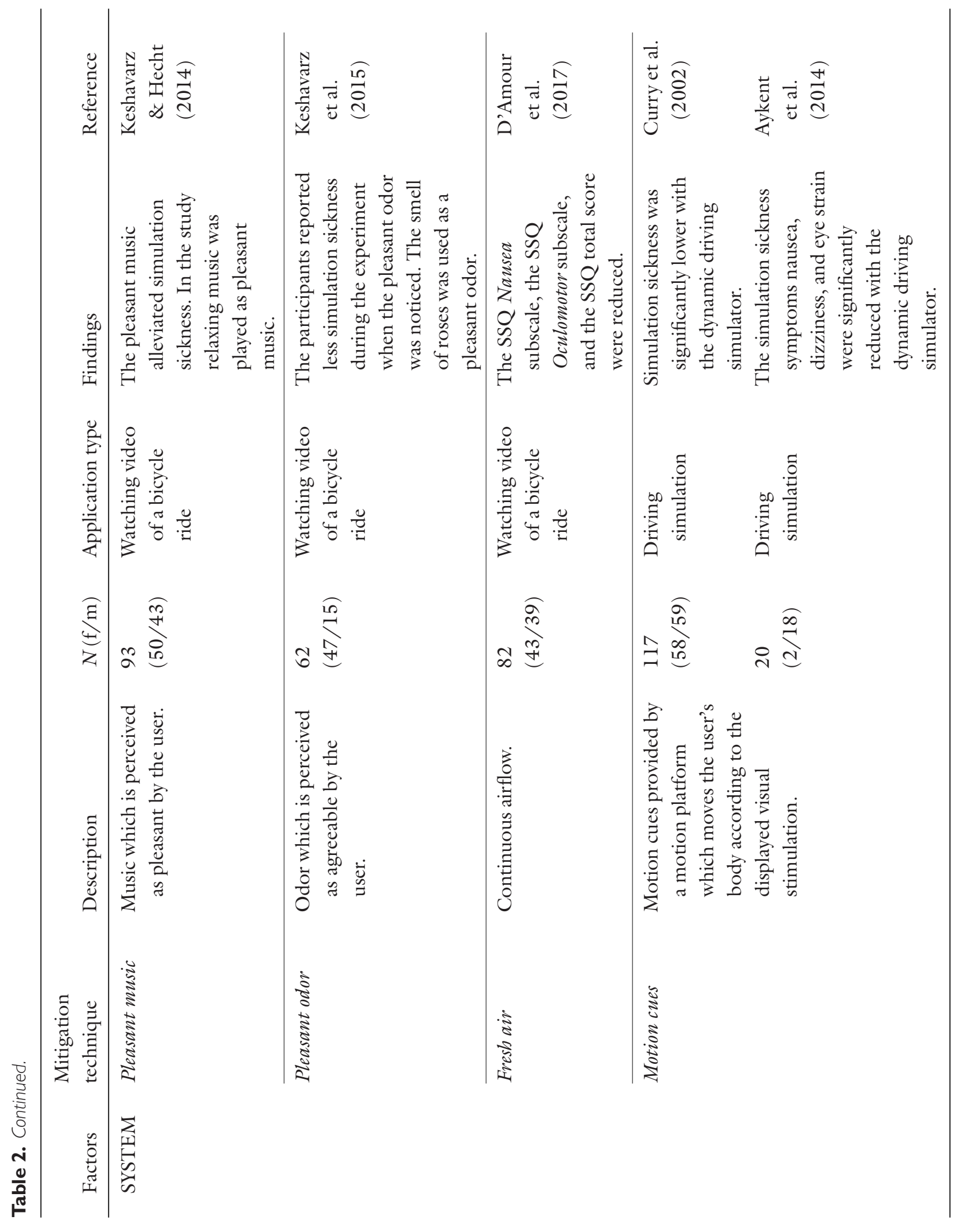




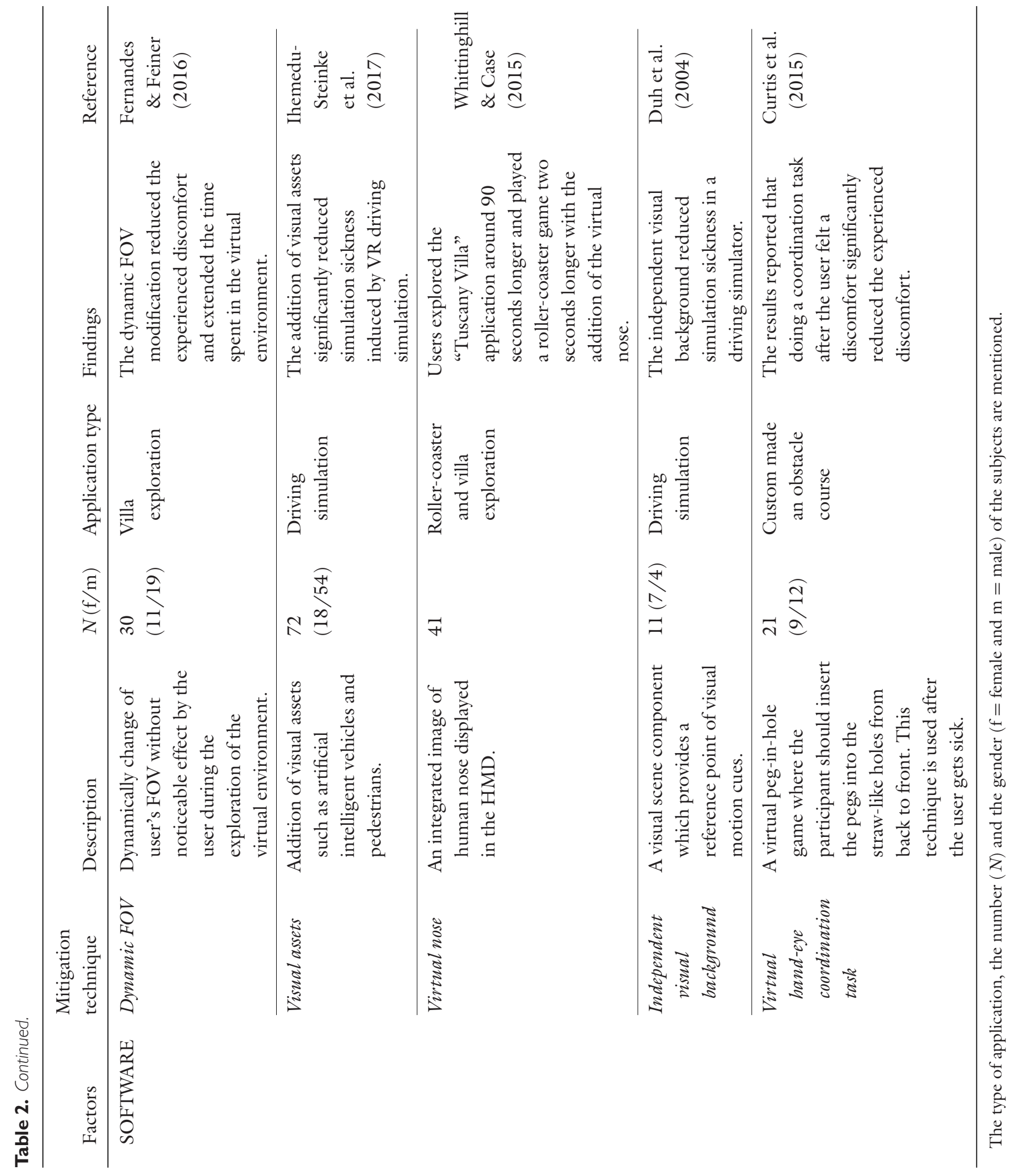


and dry mouth, which in many cases are very similar to the motion sickness symptoms, may occur (Spinks, Wasiak, Bernath, \& Villanueva, 2007). The study was conducted with the PROVISION 200 immersion VR system and attached flight helmet with a resolution of $360 \times 240$. Compared to current standards of VR technology, the used VR system has been outdated and therefore the effect of hyoscine with the current HMDs is unknown.

Lien et al. (2003) showed that ginger effectively reduced the nausea severity and even reduced the recovery period after the experiment. A cutaneous electrogastrography was used as a measurement tool for vasopressin infusion and plasma vasopressin determination. The findings confirmed that ginger could be successfully used against motion sickness and aligned with previous research on motion sickness (Grøntved, Brask, Kambskard, \& Hentzer, 1988). However, ginger only alleviates symptoms of nausea, which are primarily related to motion sickness; other Oculomotor cluster symptoms, such as disorientation or dizziness, can still affect the user. The experimental setup implemented circular vection to induce nausea and did not use any VR technology. Therefore, it can be assumed that ginger might alleviate the simulation sickness in virtual environments. Further research is needed to assess the effect of ginger on simulation sickness in VR applications.

Regan (1995) reported that adaptation is a possible technique against simulation sickness induced by HMDs. The adaptation process consisted of four immersive sessions. The time between the first, the second, and the third sessions was approximately four months. The time between the third and the last sessions was only one week. Each session followed the same instructions and used the same virtual environment as the previously conducted experiment on the frequency of occurrence and severity of side effects of immersion in VR (Regan, 1995). The measurement tools were the malaise scale and the SSQ. The results demonstrated that all participants experienced symptoms after the first session.

In contrast, $57 \%$ of the participants reported no symptoms after the last session. Although there was a slight increase in the Disorientation and Oculomotor cluster between the second and the third session, the adaptation was successful. It must be considered that all of the sessions were conducted in the same virtual environment and therefore, it can be debated that adaptation is possible only when the environment does not change. The virtual environment should consist of the same or very similar elements for which the user's body would not notice any differences.

Domeyer et al. (2013) investigated adaptation within a short period (one day) between the sessions as a mitigation technique against simulation sickness onset in a driving simulator. Each testing session was preceded by a short familiarization session with the simulator. Nevertheless, some of the test sessions were conducted on the same day as the familiarization sessions and some two days later due to the counterbalanced study design. A Revised Simulator Sickness Questionnaire (RSSQ) by Kim, Parker, and Park (2004) was used for the evaluation of simulation sickness. The RSSQ is a modified version of the SSQ that extends the SSQ with adding a subscale (strain/confusion), eight items (drowsiness, visual flashbacks, stomach awareness, confusion, vomiting, pallor, difficulty equilibrating, muscle stiffness for strain), and change the rating scale to a broader range from 1 to 10. It turned out that the adaptation process, in a sequence of a short session followed by a day of no exposure before the test session, decreased the simulation sickness symptoms induced by a driving simulator. Thus, it could be a promising option to give users a sufficient amount of time to adapt to a particular simulated environment. However, this approach is rather time- and resource-consuming.

Keshavarz et al. (2017) evaluated the effect of passive restraint of the upper body movements on simulation sickness onset in relation to age during a simulated driving task. The participants were located in two group related to their age. A Fast Motion Sickness Scale (FMS), the SSQ, and a postural sway test (with eyes closed) were used in the experiment. The FMS is a verbal rating scale ranging from 0 (no sickness at all) to 20 (frank sickness) that assesses the sickness severity at a given moment (Keshavarz \& Hecht, 2011). Additionally, a questionnaire measured the presence, simulation realism and vection. The presence was assessed using a scale from 0 (not at all) to 10 (very strong). The realism was assessed using 
a scale from 0 (very unrealistic) to 10 (very realistic). The vection was assessed using a scale from $0 \%$ (never) to $100 \%$ (constantly). After each test session, the participants were asked whether they feel sick. Following their answer (yes or no), the participants were divided into a sick and well group. The Keshavarz team reported that participants felt a higher level of realism and a stronger sense of presence during the restrained condition. No effect on vection was found in older participants in the unrestrained driving condition. Simulation sickness was significantly reduced in the restrained condition among older participants who were assigned in the sick group and experienced sickness in the unrestrained condition. Besides the positive effects, the approach of upper body restraint was not evaluated with an HMD which was reported to induce more simulation sickness compared to projection displays (Sharples, Cobb, Moody, \& Wilson, 2008 ). Furthermore, the exploration of the virtual environment is constrained due to limited movement capability, which could result in discomfort or willingness to terminate the session. Thus, further research would be needed to determine exactly how this approach affects simulation sickness induced by HMDs.

Keshavarz and Hecht (2014) reported a significant alleviation of simulation sickness when pleasant music was played during the projection of a bicycle ride video. The FMS and the SSQ were used to measure the sickness outbreak. Additionally, the participants were asked to rate the pleasantness of the music on a 7 -point Likert scale ( 1 - very pleasant, 7 - very unpleasant). The study evaluated three different types of music: relaxing instrumental music, neutral mainstream pop music, and stressful electronic music. The results of the study indicated that the relaxing music likely reduced simulation sickness.

The music was grouped by its subjective pleasantness to pleasant and unpleasant music. The participants who perceived the played music as pleasant, regardless of the type, reported less simulation sickness. Keshavarz and Hecht (2014) have drawn attention to the assumption that sounds, such as engine sounds or traffic noise, do not have any effect on simulation sickness. The background music should be part of a more complex musical piece such as instrumental or pop music. Neverthe- less, the participants' head movements were limited by a chinrest. Thus, it can be argued that the head restraint may contribute to reducing simulation sickness onset due to the reported positive effect of the passive body restraint on simulation sickness (Keshavarz et al., 2017).

Regarding VR driving simulation, the use of music might be a promising approach for mitigating simulation sickness. Music can be integrated as radio music within the car entertainment system where the user can choose between radio stations with different types of music. However, the effect of music and the different type of music on simulation sickness induced by HMDs is unknown.

Keshavarz et al. (2015) investigated the effect of different odors on simulation sickness. The FMS and the SSQ assessed simulation sickness severity. The participants were divided into three groups: pleasant odor (rose), unpleasant odor (leather), and no odor. The categorization of the odors was made according to a previous survey on odors and their level of pleasantness. The experimental setup was identical to a previously conducted experiment investigating the different type of music and simulation sickness (Keshavarz \& Hecht, 2014). It has been found that only half of the participants who were exposed to the scents were able to notice the different scent. Thus, these data were reassigned to a fourth group (odor not noticed). Results showed that simulation sickness onset was significantly reduced with the addition of pleasant odor compared to the group that did not detect any the odor. These findings point out that not every user will be affected by a pleasant odor and consequently will experience less discomfort due to highly subjective scent preferences.

Furthermore, it can be argued that the head restraint, identical to the previous study (Keshavarz \& Hecht, 2014), may contribute to reducing simulation sickness onset due to the reported positive effect of the passive body restraint on simulation sickness (Keshavarz et al., 2017). The effect of pleasant odor on simulation sickness induced by HMD during driving applications is unknown. Nevertheless, the use of a pleasant odor, as a subtle air refresher, might be a potential method for minimizing simulation sickness. 
D'Amour et al. (2017) found out that a continuous stream of fresh air directed to the user significantly reduced simulation sickness. The FMS and the SSQ measured the sickness outbreak. The experiment setup was similar to previous studies (Keshavarz \& Hecht, 2014; Keshavarz et al., 2015) except that the restraint of the head movements was removed; two fans streaming airflow to the participant and vibration to the participant's seat were added. The participants were assigned to one of the following groups: control (no airflow and no vibration), airflow, vibration, and airflow and vibration. Only the approach of fresh air is added as a mitigation technique in Table 2 because the other approach showed no significant results regarding simulation sickness. The study has shown that the airflow can be quickly provided by fans which stream cool fresh air to the user. This technique is appropriate for almost every VR driving application. Moreover, this method can aid in sustaining the body temperature at a comfortable level during the simulation to reduce discomfort.

Curry et al. (2002) compared static and dynamic driving simulators regarding the severity of simulation sickness in virtual environments. The sickness outbreak was measured by SSQ which, in contrast with the studies above, was administrated verbally. It has been found that the dynamic driving simulator significantly reduced simulation sickness compared to the static one. The study included an acclimation time of approximately five to ten minutes. It can be argued that the addition of motion cues did not solely reduce simulation sickness but rather the combination between the acclimation time and the motion cues also aided in this particular experiment. Nonetheless, it is a standard procedure of driving simulation studies to include an acclimation time before the actual driving evaluation. The addition of a motion platform to a static VR driving simulation has the potential to reduce the simulation sickness onset.

Aykent et al. (2014) found out that simulation sickness was significantly reduced with a dynamic driving simulator compared to a static one, which has been in line with Curry et al. (2002). The method of measurement was a Motion Sickness Dose Value (MSDV) and a questionnaire on perception due to psychophysics. The MSDV is a method for objectifying the motion sick- ness rating. The coefficients used in this method are calculated by the frequency and direction of vibration to which the body is exposed (ISO 2631-1:1997). In this study, Aykent, Merienne, and colleagues (2014) applied an illness rating method originated from the MSDV where the scores were ranging from 0 ("I felt good") to 3 and greater than 3 ("I felt absolutely terrible"). The longitudinal, lateral, and vertical acceleration from the head of the participants were used to determinate the illness rating. The questionnaire on perception contained 12 items measured from 1 (very little) to 10 (very strong). The purpose of the questionnaire was to assess not only the perceived physical discomfort, like in the SSQ, but also to assess the participants' impressions (psychophysics), such as mental pressure, fear, and anxiety. Results showed that nausea, dizziness, and eye strain symptoms had lower values compared to the static driving simulator.

Moreover, it was observed that longitudinal head movements induced discomfort with the static driving simulator and vertical head movements induced discomfort with the dynamic driving simulator. The addition of physical motion cues is a promising approach to alleviate simulation sickness which can be applied to VR driving simulations. Nevertheless, it might bring a nauseous effect originated by a moving vehicle, such as motion sickness and should, therefore, be applied with caution.

Fernandes and Feiner (2016) were able to show that a subtle dynamic change of the FOV reduced simulation sickness. The FOV was changing dynamically until it reached $80^{\circ}$ or $90^{\circ}$ soft-edged cutout FOV displayed on the HMD. The measurement tools were the SSQ, the PQ and a discomfort score obtained by a question regarding the current state of discomfort graded from 0 ("how you felt coming in") to 10 ("want to stop"). Additionally, a post-questionnaire was used to assess whether the participants noticed the FOV constraints and if they did whether the constraints restricted their experience. This technique allowed participants to immerse in the virtual environment and experience less discomfort while exploring the virtual world. The finding suggested that the changed FOV is subtle and did not disrupt the level of presence. However, a reduced FOV 
decreases the level of presence (Cummings \& Bailenson, 2015). The dynamically reduced FOV might be not entirely applicable to VR driving applications due to the restriction of the exploration and immersion of the virtual environment. Nonetheless, further research with a focus on this approach regarding simulation sickness in HMD driving applications is necessary before coming to any concrete conclusions.

Ihemedu-Steinke et al. (2017) evaluated the effect of the addition of visual assets (e.g., artificial intelligent vehicles and pedestrians) on simulation sickness in a VR driving simulation. For the evaluation, the SSQ and a questionnaire to assess the virtual experience and enjoyment based on the PQ and a measurement tool by Lin et al. (2002) were used. Results showed that the participants experienced significantly less sickness when the driving simulation included the additional visual assets. The study did not report the previous VR experience of the participants. Therefore, it is unclear whether they were using an HMD for the first time or they had previous experience. The excitement of using a VR technology for the first time could have suppressed the experienced discomfort, and therefore, the participants stayed longer immersed despite the felt discomfort. As another study indicated, the participants may still enjoy the VR experience regardless of simulation sickness (von Mammen, Knote, \& Edenhofer, 2016); the group with additional visual assets drove a little more than one minute longer than the other group. Thus, a mitigation technique of including visual assets can be a possible solution against simulation sickness in a short VR driving session (5-10 $\mathrm{min})$. The approach of adding visual assets could enhance the VR experience not only by reducing simulation sickness outbreak, but also by improving realism.

Whittinghill et al. (2015) reported simulation sickness reduction by adding a virtual nose to the center of FOV of the HMD. The time duration was recorded as well as the electrodermal activity. The results showed a time delay of a few seconds before the sickness was acknowledged. This time delay is not sufficient for VR driving applications where a delay of a few seconds would not make a notable difference for the users. Their findings might have been more persuasive if more in- formation about the research was given. The approach of adding a virtual nose is not entirely applicable to VR driving applications due to extensive user evaluation sessions.

Duh et al. (2004) investigated the effect of an independent visual background on simulation sickness in a driving simulator. The SSQ was used for simulation sickness symptoms assessment. The E2i Questionnaire was used for assessment of "sense of presence" and "enjoyment." This questionnaire was developed to assess engagement, enjoyment and immersion in a virtual environment (Lin, Abi-Rached, Kim, \& Parker, 2002; Lin, Duh et al., 2002). The participants reported significantly fewer symptoms with the independent visual background than the no-visual background condition. A possible flaw of this approach is that the sense of presence might be interrupted. Contrary to that, the results showed that the sense of presence and enjoyment were slightly higher in the independent visual background condition. However, the small sample size failed to deliver evidence for a conclusive decision. The addition of independent visual background has the potential to be applied against simulation sickness in HMD driving applications.

Curtis et al. (2015) proposed a mitigation technique of a virtual hand-eye coordination task against simulation sickness. The SSQ assessed the induced sickness, the mitigation effectiveness, and the sickness outbreak. The study reported a significant decrease of simulation sickness symptoms. Moreover, the authors pointed out that the participants carried out the task while they were still immersed in the virtual environment. Regarding VR driving simulations, this approach is not entirely suitable due to a possible distracting effect on the driver. Nonetheless, this approach possibly may be helpful, for VR fully autonomous driving simulations, to keep the users longer in the virtual environment without interrupting the immersion.

\section{Conclusion}

This article has given an overview and described recent studies, as well as discussed mitigation techniques 
for simulation sickness. Although simulation sickness has been one of the drawbacks of virtual reality technology, a concrete solution to this problem has still not been found. This work contributes to existing knowledge of simulation sickness by presenting an overview of possible approaches to mitigate simulation sickness. Each approach is categorized in one of the three categories and it is shortly described. Furthermore, all approaches are separately critically reviewed from the perspective of HMD driving simulations. The findings of the study suggest that mitigation techniques, such as the addition of visual assets, motion cues, or continuous airflow, can be integrated into the VR driving applications to alleviate simulation sickness outbreak.

The addition of visual assets can contribute as well to the element of realism which gives the illusion that the simulation is close to reality. The feeling of being in an artificial environment is suppressed and the discrepancy between the user expectations and the actual simulation is reduced. However, the simulation environment should not be overpopulated with artificially intelligent vehicles, bicycle riders or pedestrians because this could lead to disorientation (which object to be visually followed), headache or eye strain (which object to focus on).

The addition of motion cues can contribute to the element of realism as well. Very often the static driving simulation lacks motion cues and a conflict between the visual and vestibular systems arises. In line with the cue conflict theory, this conflict could be suppressed with correctly simulated motion cues, which replicate the visual motion on a physical level. Nevertheless, if the motion cues are not synchronized with the visual cues, it is better to use the driving simulation without any physical motion (Schöner \& Morys, 2016).

Some of the mitigation techniques have already been tested with VR driving applications and yielded to positive results. Others have been successfully tested with simulation sickness stimuli which give prospects to be applied with HMD driving applications. Additionally, this work has shown that the mitigation techniques could incorporate more than one technique unintentionally. For example, combination of two techniques such as pleasant music and head restraint (Keshavarz
\& Hecht, 2014), pleasant odor and head restraint (Keshavarz et al., 2015), and acclimation time and motion cues (Curry et al., 2002). Depending on the objective of the user evaluation, specific factors related to simulation sickness should be considered during the development of the VR driving simulation. The improvement of the hardware (e.g., central processing unit, graphics processing unit and HMD performance) and also, the right setup could reduce some of the factors (e.g., refresh rate, FOV, and flicker).

This article has underlined the importance of further research on simulation sickness evaluation in HMD virtual environments. Future VR driving simulators should aim for a high level of immersion with a low level of discomfort. The main point of the VR simulation should be to convince the human body that whatever is seen is real. Nonetheless, the level of immersion contributes to the level of presence which is positively related to simulation sickness outbreak. The modern HMDs include a wide FOV which contributes to a higher level of presence. However, the same wide FOV contributes to simulation sickness symptoms. More than one technique can be used to mitigate the sickness onset to cover different aspects of sickness induced factors. Future research is needed to give comprehensive information about the correlation between individual, system and task-related factors regarding simulation sickness. Moreover, further research should be carried out with state-of-the-art HMDs due to better resolution, ergonomics, and low latency.

\section{References}

Aykent, B., Merienne, F., Guillet, C., Paillot, D., \& Kemeny, A. (2014). Motion sickness evaluation and comparison for a static driving simulator and a dynamic driving simulator. Journal of Automobile Engineering, 288(7), 818-829. Retrieved from https://doi.org/10.1177 $/ 0954407013516101$

Aykent, B., Yang, Z., Merienne, F., \& Kemeny, A. (2014). Simulation Sickness Comparison between a Limited Field of View Virtual Reality Head Mounted Display (Oculus) and a Medium Range Field of View Static Ecological Driving Simulator (ECO2). 
Biocca, F. (1992). Will simulation sickness slow down the diffusion of virtual environment technology? Presence: Teleoperators and Virtual Environments, 1, 334-343.

Brooks, J. O., Goodenough, R. R., Crisler, M. C., Klein, N. D., Alley, R. L., Koon, B. L., ... Wills, R. F. (2010). Simulator sickness during driving simulation studies. Accident Analysis \& Prevention, 42(3), 788-796. Retrieved from https://doi.org/http://dx.doi.org/10.1016/j.aap.2009 .04 .013

Cobb, S. V. G., Nichols, S., Ramsey, A., \& Wilson, J. R. (1999). Virtual reality-induced symptoms and effects (VRISE). Presence: Teleoperators and Virtual Environments, $8(2)$, 169-186. Retrieved from https://doi.org/10.1162 $/ 105474699566152$

Colombet, F., Kemeny, A., \& George, P. (2016). Motion sickness comparison between a CAVE and a HMD. Driving Simulation Conference Europe, 201-208.

Costello, P. (1997). Health and safety issues associated with virtual reality-A review of current literature. Advisory Group on Computer Graphics, 37, 371-375.

Crampton, G. (1990). Motion and space sickness. Boca Raton, FL: CRC Press.

Crowley, J. S. (1987). Simulator sickness: A problem for Army aviation. Aviation, Space, and Environmental Medicine, $58(4), 355-357$.

Cummings, J. J., \& Bailenson, J. N. (2015). How immersive is enough? A meta-analysis of the effect of immersive technology on user presence. Media Psychology, 3269, 1-38. Retrieved from https://doi.org/10.1080/15213269.2015 .1015740

Curry, R., Artz, B., Cathey, L., Grant, P., \& Greenberg, J. (2002). Kennedy SSQ results: Fixed- vs. motion-base Ford simulators. Driving Simulation Conference, 1-11.

Curtis, M. K., Dawson, K., Jackson, K., Litwin, L., Meusel, C., Dorneich, M. C., ... Winer, E. (2015). Mitigating visually induced motion sickness. Proceedings of the Human Factors and Ergonomics Society Annual Meeting, 59(1), 1839-1843. Retrieved from https://doi.org/10.1177 $/ 1541931215591397$

D'Amour, S., Bos, J. E., \& Keshavarz, B. (2017). The efficacy of airflow and seat vibration on reducing visually induced motion sickness. Experimental Brain Research, 235(9), 2811-2820. Retrieved from https://doi.org/10.1007 /s00221-017-5009-1

Davis, S., Nesbitt, K., \& Nalivaiko, E. (2015). Comparing the onset of cybersickness using the Oculus Rift and two virtual roller coasters. 11th Australasian Conference on Interactive Entertainment, 27-30. Retrieved from https://doi.org/10.17973/MMSJ.2015

De Winter, J., Van Leeuwen, P. M., \& Happee, R. (2012). Advantages and disadvantages of driving simulators: A discussion. Proceedings of Measuring Behavior, 4750

Domeyer, J. E., Cassavaugh, N. D., \& Backs, R. W. (2013). The use of adaptation to reduce simulator sickness in driving assessment and research. Accident Analysis and Prevention, 53, 127-132. Retrieved from https://doi.org/10.1016/j.aap.2012.12.039

Duh, H., Parker, D., \& Furness, T. (2004). An independent visual background reduced simulator sickness in a driving simulator. Presence: Teleoperators and Virtual Environments, 13(5), 578-588. Retrieved from https://doi.org/10.1162/1054746042545283

Eudave, L., \& Valencia, M. (2017). Physiological response while driving in an immersive virtual environment. IEEE 14th International Conference on Wearable and Implantable Body Sensor Networks, 145-148. Retrieved from https://doi.org/10.1109/BSN.2017.7936028

Fernandes, A. S., \& Feiner, S. K. (2016). Combating VR sickness through subtle dynamic field-ofview modification. Proceedings of 2016 IEEE Symposium on 3D User Interfaces, 201-210. Retrieved from https://doi.org/10.1109/3DUI.2016.7460053

Gálvez-García, G. (2015). A comparison of techniques to mitigate simulator adaptation syndrome. Ergonomics, 58(8), 1365-1371. Retrieved from https://doi.org/10.1080/00140139.2015.1005168

Grøntved, A., Brask, T., Kambskard, J., \& Hentzer, E. (1988). Ginger root against seasickness: A controlled trial on the open sea. Acta Oto-Laryngologica, 105(12), 45-49. Retrieved from https://doi.org/10.3109 $/ 00016488809119444$

Ihemedu-Steinke, Q. C., Rangelova, S., Weber, M., Erbach, R., Meixner, G., \& Marsden, N. (2017). Simulation sickness related to virtual reality driving simulation. VAMR 2017, held as part of HCI International, 521-532. Vol. 10280. Retrieved from https://doi.org/10.1007/978-3-319 -57987-0_42

Ihemedu-Steinke, Q. C., Sirim, D., Erbach, R., Halady, P., \& Meixner, G. (2015). Development and evaluation of a virtual reality driving simulator. In A. Weisbecker, M. Burmester, \& A. Schmidt (Eds.), Mensch \& computer workshopband (pp. 491-500). Boston: De Gruyter Oldenbourg. 
ISO 2631-1:1997. (1997). Mechanical vibration and shockEvaluation of human exposure to whole-body vibrationPart 1: General requirements. Retrieved from https://www .iso.org/standard/7612.html

Jinjakam, C., \& Hamamoto, K. (2012). Simulator sickness in immersive virtual environment. In Biomedical Engineering International Conference, 1-4. Retrieved from https://doi.org/10.1109/BMEiCon.2012.6465465

Johnson, D. M. (2005). Introduction to and review of simulator sickness research. Research Report 1832. Social Sciences. Retrieved from https://doi.org/Research_Report _1832_23

Kennedy, R. S., Berbaum, K. S., Lilienthal, M. G., Dunlap, W. P., \& Mulligan, B. E. (1987). Guidelines for Alleviation of Simulator Sickness Symptomatology. Technical Report No. TR-87-007. Orlando, FL: Naval Training Systems Center. Kennedy, R. S., \& Fowlkes, J. E. (1992). Simulator sickness is polygenic and polysymptomatic: Implications for research. The International Journal of Aviation Psychology, 2(1), 23-38. Retrieved from https://doi.org/10.1207 /s15327108ijap0201_2

Kennedy, R. S., Lane, N. E., Berbaum, K. S., \& Lilienthal, M. G. (1993). Simulator sickness questionnaire: An enhanced method for quantifying simulator sickness. The International Journal of Aviation Psychology, 3(3), 203-220. Retrieved from https://doi.org/10.1207 /s15327108ijap0303_3

Kennedy, R. S., \& Lilienthal, M. G. (1995). Implications of balance disturbances following exposure to virtual reality systems. Proceedings of Virtual Reality Annual International Symposium, 35-39.

Keshavarz, B. (2016). Exploring behavioral methods to reduce visually induced motion sickness in virtual environments, 9740, 147-155. Retrieved from https://doi.org/10.1007 /978-3-319-39907-2

Keshavarz, B., \& Hecht, H. (2011). Validating an efficient method to quantify motion sickness. Human Factors: The Journal of the Human Factors and Ergonomics Society, 53(4), 415-426. Retrieved from https://doi.org/10.1177 $/ 0018720811403736$

Keshavarz, B., \& Hecht, H. (2014). Pleasant music as a countermeasure against visually induced motion sickness. Applied Ergonomics, 45(3), 521-527. Retrieved from https://doi.org/https://doi.org/10.1016/j.apergo.2013 .07 .009

Keshavarz, B., Hecht, H., \& Lawson, B. D. (2014). Visually induced motion sickness: Causes, characteristics, and countermeasures. In K. M. Stanney \& K. Hale (Eds.), Handbook of virtual environments: Design, implementation, applications (2nd ed., pp. 647-697). New York: CRC Press.

Keshavarz, B., Novak, A. C., Hettinger, L. J., Stoffregen, T. A., \& Campos, J. L. (2017). Passive restraint reduces visually induced motion sickness in older adults. Journal of Experimental Psychology: Applied, 23(1), 85-99. Retrieved from https://doi.org/10.1037/xap0000107

Keshavarz, B., Stelzmann, D., Paillard, A., \& Hecht, H. (2015). Visually induced motion sickness can be alleviated by pleasant odors. Experimental Brain Research, 233(5), 1353-1364. Retrieved from https://doi.org/10.1007 /s00221-015-4209-9

Kim, D., Parker, D., \& Park, M. (2004). A new procedure for measuring simulator sickness - The RSSQ. Technical Report R-2004-52. Human Interface Technology Laboratory, University of Washington.

Kim, M. S., Moon, Y. G., Kim, G. D., \& Lee, M. C. (2010). Partial range scaling method based washout algorithm for a vehicle driving simulator and its evaluation. International Journal of Automotive Technology, 11(2), 269-275. Retrieved from https://doi.org/10.1007/s12239-010 -0034-0

Kolasinski, E. M. (1995). Simulator sickness in virtual environments. United States Army Research Institute for the Behavioral and Social Sciences. Retrieved from https://doi.org /10.1121/1.404501

Lien, H.-C., Sun, W. M., Chen, Y.-H., Kim, H., Hasler, W., \& Owyang, C. (2003). Effects of ginger on motion sickness and gastric slow-wave dysrhythmias induced by circular vection. American Journal of Physiology-Gastrointestinal and Liver Physiology, 284(3), G481-G489. Retrieved from https://doi.org/10.1152/ajpgi.00164.2002

Lin, J. J.-W., Abi-Rached, H., Kim, D.-H., \& Parker, D. E. (2002). A "natural" independent visual background reduced simulator sickness. Human Factors and Ergonomics Society, 2202-2205. Retrieved from https://doi.org/10.1177 /154193120204602605

Lin, J. J. W., Duh, H. B. L., Parker, D. E., Abi-Rached, H., \& Furness, T. A. (2002). Effects of field of view on presence, enjoyment, memory, and simulator sickness in a virtual environment. Proceedings of Virtual Reality, 164171. Retrieved from https://doi.org/10.1109/VR.2002 .996519

McCauley, M. E. (1984). Research issues in simulator sickness: Proceedings of a workshop. New York: National Academies. 
Nichols, S., Haldane, C., \& Wilson, J. R. (2000). Measurement of presence and its consequences in virtual environments. International Journal of Human-Computer Studies, 52, 471-491. Retrieved from https://doi.org/10.1006 /ijhc.1999.0343

Oculus Rift. (2018). Retrieved from https://www.oculus .com/rift/\#oui-csl-rift-games=robo-recall

Popa, J., Oculus Rift: DKl vs DK2. (2014). Retrieved from http://in2gpu.com/2014/08/10/oculus-rift-dk1-vs-dk2/

Reason, J., \& Brand, J. J. (1975). Motion sickness. New York: Academic Press.

Regan, C. (1995). An investigation into nausea and other sideeffects of head-coupled immersive virtual reality. Virtual Reality, 1(1), 17-32.

Reich, D., Buchholz, C., \& Stark, R. (2017). Methods to validate automotive user interfaces within immersive driving environments (pp. 429-454). Berlin: Springer International Publishing. Retrieved from https://doi.org/10.1007 /978-3-319-49448-7_16

Riccio, G. E., \& Stoffregen, T. A. (1991). An ecological theory of motion sickness and postural instability. Ecological Psychology, 3(3), 195-240. Retrieved from https://doi.org /10.1207/s15326969eco0303

Schöner, H.-P., \& Morys, B. (2016). Dynamic driving simulators. In Handbook of driver assistance systems (pp. 177-198). Cham: Springer International Publishing. Retrieved from https://doi.org/10.1007/978-3-319-12352-3

Schuemie, M. J., Van der Straaten, P., Krijn, M., \& Van der Mast, C. A. P. (2001). Research on presence in VR: A survey. CyberPsychology and Behavior, 4(2), 183-201. Retrieved from https://doi.org/10.1089/109493101300117884

Sharples, S., Cobb, S., Moody, A., \& Wilson, J. R. (2008). Virtual reality induced symptoms and effects (VRISE): Comparison of head mounted display (HMD), desktop and projection display systems. Displays, 29(2), 58-69. Retrieved from https://doi.org/http://dx.doi.org/10.1016 /j.displa.2007.09.005

Sieber, M., Berg, G., Karl, I., Siedersberger, K.-H., Siegel, A., \& Farber, B. (2013). Validation of driving behaviour in the vehicle in the loop: Steering responses in critical situations. 16th International IEEE Conference on Intelli- gent Transportation Systems, 1101-1106. Retrieved from https://doi.org/10.1109/ITSC.2013.6728379

Spinks, A., Wasiak, J., Bernath, V., \& Villanueva, E. (2007). Scopolamine (hyoscine) for preventing and treating motion sickness. In J. Wasiak (Ed.), Cochrane database of systematic reviews (p. CD002851). Chichester, UK: John Wiley \& Sons, Ltd. Retrieved from https://doi.org/10.1002 /14651858.CD002851.pub3

Treisman, M. (1977). Motion sickness: An evolutionary hypothesis. Science, 197(4302), 493-495.

Uliano, K. C., Lambert, E. Y., Kennedy, R. S., \& Sheppard, D. J. (1986). The Effects of Asynchronous Visual Delays on Simulator Flight Performance and the Development of Simulator Sickness Symptomatology. Preliminary Final Report No. NAVTRASYSCEN 85-0-9926-1. Orlando, FL: Naval Training Center.

von Mammen, S., Knote, A., \& Edenhofer, S. (2016). Cyber sick but still having fun. Proceedings of the 22nd ACM Conference on Virtual Reality Software and Technology, 325326. Retrieved from https://doi.org/10.1145/2993369 .2996349

Walch, M., Hock, P. Frommel, J., Dobbelstein, D., Rogers, K., Weber, M., \& Schüssel, F. (2017). Evaluating VR driving simulation from a player experience perspective. In Proceedings of the 2017 CHI Conference Extended Abstracts on Human Factors in Computing Systems, 29822989. Retrieved from https://doi.org/10.1145/3027063 .3053202

Weidner, F., Hoesch, A., Poeschl, S., \& Broll, W. (2017). Comparing VR and non-VR driving simulations: An experimental user study. IEEE Virtual Reality, 281-282. Retrieved from https://doi.org/10.1109/VR.2017.7892286

Whittinghill, J., \& Case, T. (2015). Nasum virtualis: A simple technique for reducing simulator sickness. Games Developers Conference.

Witmer, B. G., \& Singer, M. J. (1998). Measuring presence in virtual environments: A presence questionnaire. Presence: Teleoperators and Virtual Environments, 7(3), 225-240. Retrieved from https://doi.org/10.1162/105474698565686

XSens. (2010). XSens Technologies BV15. Mti and mtx user manual and technical documentation, document MT0100P. 